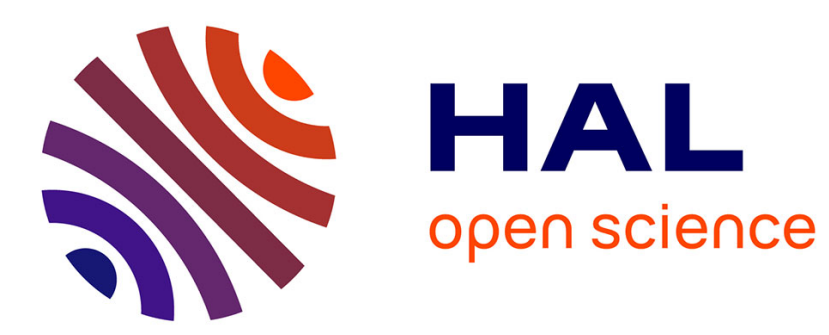

\title{
Digital Factories for Capability Modeling and Visualization
}

\author{
Farhad Ameri, Ramin Sabbagh
}

\section{To cite this version:}

Farhad Ameri, Ramin Sabbagh. Digital Factories for Capability Modeling and Visualization. IFIP International Conference on Advances in Production Management Systems (APMS), Sep 2016, Iguassu Falls, Brazil. pp.69-78, 10.1007/978-3-319-51133-7_9 . hal-01615781

\section{HAL Id: hal-01615781 \\ https://hal.inria.fr/hal-01615781}

Submitted on 12 Oct 2017

HAL is a multi-disciplinary open access archive for the deposit and dissemination of scientific research documents, whether they are published or not. The documents may come from teaching and research institutions in France or abroad, or from public or private research centers.
L'archive ouverte pluridisciplinaire HAL, est destinée au dépôt et à la diffusion de documents scientifiques de niveau recherche, publiés ou non, émanant des établissements d'enseignement et de recherche français ou étrangers, des laboratoires publics ou privés. 


\title{
A Communication Procedure between Tactical and Operational Levels in Spare Parts Supply Chains
}

\author{
Matheus Cardoso Pires ${ }^{1}$, Enzo Morosini Frazzon ${ }^{1}$ Ann-Kristin Cordes ${ }^{2}$ Bernd Hellin- \\ grath $^{2}$ \\ ${ }^{1}$ Universidade Federal de Santa Catarina, Florianópolis, Brazil \\ enzo.frazzon@ufsc.br, matheus.pires@grad.ufsc.br \\ ${ }^{2}$ Westfälische Wilhelms-Universität Münster \\ cordesdercis.uni-muenster.de, bernd.hellingrathewi.uni- \\ muenster.de
}

\begin{abstract}
Supply Chain Management has been an important issue for competitiveness in today's market. Different decision-support models focus on specific time horizons and goals. The most common way of structuring supply chain planning process is dividing it in three different levels: operational, tactical and strategic. However, the planning on one level generally does not communicate with the others, limiting its efficiency and feasibility. The present work proposes a communication procedure between tactical and operation support-decision models in order to coordinate both, thus improving their overall performance. The procedure will be applied to a test case comprising a Spare Parts Supply Chain (SPSC) problem for maintenance in production facilities with the concept of integrating spare parts supply chain and intelligent maintenance systems implemented.
\end{abstract}

Keywords: Supply chain $\cdot$ Planning $\cdot$ Management $\cdot$ Integrated planning $\cdot$ Operations research

\section{Introduction}

A Supply Chain (SC) can be defined as a network of organizations, flows, and processes where companies work to transform raw material in final products delivered to a customer. [1] Presents Supply Chain Management (SCM) as the study of resources of enterprises and human decisions in relation to cross-enterprise collaboration processes to transform and use these resources in the most rational way along the entire value chain, from customers up to raw material suppliers, based on functional and structural integration, cooperation, and coordination throughout. The author classifies

adfa, p. 1, 2011.

(C) Springer-Verlag Berlin Heidelberg 2011 
SCM as the most popular strategy for improving organizational competitiveness in the twenty-first century.

Supply Chain planning can be seen as a set of goals, performance indicators and decisions to be taken in order to optimize the SC performance. The Supply Chain Planning comes in different levels of application, each one focusing in actions that fit its time horizon and goals. The Strategic Planning is on the top of the pyramid, and consists in long-term decision and goals, as desired service level and facilities location. In the middle of the pyramid is placed the Tactical Planning, working on midterm decisions what includes the allocation of production and transports capacities, for example. At the bottom of the pyramid, the Operational Planning takes care of the daily decisions, as transport strategies and production scheduling.

All the levels of planning are necessary in SCs planning. However, these planning are usually built without communicating with the other, in despite of the fact that the efficiency and applicability of the output of each plan can decrease if the different levels of planning are considered in isolation of each other [2].

This research paper aims to develop a communication procedure between the operational planning and tactical planning of a spare parts supply chain. To reach this objective, a flowchart comprising the planning steps of each level as well as mutual feedbacks between the decision-support models will be proposed.

The paper is organized in three sections. In the Literature Review section, a brief contextualization about the state of the art of the studying will be presented, as well as a contextualization about the emerging concept of integration between spare parts supply chain and intelligent maintenance systems wherein the output of the paper is intended to be used. In the second section, the communication procedure will be proposed by means of a test case. In the last section, the results will be discussed and the work summarized.

\section{$2 \quad$ Literature Review}

\subsection{Supply Chain Management}

According to Christopher [3] Supply Chain Management (SCM) is the management of upstream and downstream relationships with suppliers and customers to deliver superior customer value as less cost to the supply chain as a whole. Therefore, SCM becomes an interesting object of study, widely addressed by numerous approaches, being needed in any product factoring and flow around the world.

Supply Chain Management seeks to link and coordinate processes from different entities (as customers and suppliers) and to organize them [3]. This add an enormous level of complexity in decision making, once each action should not just consider each company limitation and goals, but all limitations and requirements from other agents present in the SC.

According to [4] considerable work has been invested in developing decision methods for overcoming supply chain issues, which generally adopt conventional approaches as mathematical programming (optimization), simulation and heuristics. 
These models can be very helpful since they assist managers to overcome the dimensions of the mental models for Supply Chains and provide non-biased results, helping to deal with the high complexity of considering a big number of agents, limitation, goal and variables in the system.

According to [1] decision-supporting methods can be divided in optimization, simulation and heuristics, where the optimization has been very visible and influential for the operations management. However, there is a challenge in the optimization development that consists in developed a well detailed model that can represent the reality of the supply chain at the same time it keeps simple enough to be solved with a relative low processing cost. High computational costs could turn the planning, especially on an operational level, impracticable, since it could require too much time to be executed that its results become obsolete. Since the aggregation of both tactical and operational planning levels in a single model would probably require high computational power to be solved, the goal of the present work is to describe a procedure of communication between two models.

\subsection{Spare Parts Supply Chain}

Spare parts need to be available in the right place within the supply chain, to ensure the desired level of service. However, several aspects make this task complicated, such as: the high number of parts to be managed, high responsibility required due to customer downtime costs, and the risk of obsolete inventory. Among these problems, according to [5], "due to the high costs for spare parts and their sporadic demand, keeping inventories of all parts at all warehouses in the spare parts network are not economical". Also, SCs are thus characterized by distinct, yet mutually interdependent decision domains with in-dependent business objectives. This way, the capability of existing models for supporting an intelligent and flexible synchronization and coordination of the involved process is limited. Given this intertwined and complex aspects, management processes of spare parts supply chain (SPSC) cover different areas of knowledge, which, in turn, use various resources, methods, techniques for solving coordination problems.

Some features of SPSC can be highlighted in the literature. First, the demand for spare parts usually has an intermittent and/or erratic character, making more difficult the forecasting process by classical statistical methods and inventory control [6]. The second characteristic relates to high levels of required services. Components for maintenance need to be available as soon as a fault occurs, otherwise the productive systems may be unavailable, causing high costs for the production facility [7]. Another feature derives from the two previous characteristics, as there is a wide variation in demand and a network of well-lined stocks, distribution costs are high. In periods of low demand, inventories are still needed for high demand periods, implying more expensive distribution process [8].

Having seen these concepts, detailed planning of the spare parts supply chain is necessary in order to meet service levels while minimizing costs. Furthermore, not only the planning but also the coordination between different levels and actors can be seen as a relevant topic, considering the autonomy of the different actors involved in 
the supply chain coordination. The collaboration can be reached through exchanging relevant data from multiple individual planning domains (e.g. demand planning, master planning, production planning, etc.), aiming to design a collaborative planning concept $(\mathrm{CP})$. But the applicability of existing $\mathrm{CP}$ approaches for coordinating the different autonomous actors in heterarchical SPSCs has not yet been investigated [5]. The portability of $\mathrm{CP}$ approaches to other scenarios is still an open research issue, especially to a SPSC scenario.

\subsection{Integrating Intelligent Maintenance Systems and Spare Parts Supply Chain}

The Integrating Intelligent Maintenance Systems and Spare Supply Chain (I2MS2C) concept is proposed to approach the challenge of simultaneously coping with the constraints and specificities of Intelligent Maintenance Systems (IMS) and Spare Parts Supply Chain (SPSC). The primary objective of the I2MS2C is the improvement of the effectiveness and efficiency of service management operations for complex technical systems. This will be achieved by integrating information provided by embedded IMS systems with planning and coordination methods and processes in the spare parts supply chain. On the other way around, maintenance operation benefits from an improved planning of the service operation synchronizing service demands with spare parts availability and servicing capacities.

From the technological perspective, the goal is to improve IMS capabilities in order to achieve more reliable estimations of maintenance needs. The use of intelligent maintenance technology will predict future failures in components allowing the operator to react directly on the component degradation. Besides, through techniques of mixed reality integrated into an Intelligent Maintenance System, we intend to bring relevant data about the components and machines aiding thus the provision of information to operators and service personnel.

To achieve these goals, the I2MS2C concept is divided into four main elements of the model. Research on IMS will in the following be related to the first element. Here, the concept aims at developing improved spare parts planning methods integrating IMS information and the coordination of the spare parts supply chain's actors. The focus relies on the extension and development of spare part-specific mid-term forecasting and planning methods in the domain of inventory and transportation planning. The IMS used in this project is based on the Watchdog Agent (WA), developed by the IMS center [9].

The second element of the I2MS2C concept aims to integrate the planning domains into a supply chain-wide coordination concept which also includes tactical production and maintenance service planning methods. Methods for planning short-term decisions of the supply chain actors as well as their coordination are developed in third element. Here, the interconnections to the tactical planning layer have to be regarded. The focus relies on short-term inventory planning, transportation and production scheduling. Both layers, tactical as well as operational planning, are restricted to the improvement of pro-active supply chain planning. In other words, this means that supply chain planning not include issues of reacting upon concrete machine break- 
down alerts, i.e. only failure forecasts of the IMS are included. Also, the integration architecture of the overall research work was built upon a Service Oriented Architecture (SOA), and is a cloud-based system and each entity is built as a device, following the Device Profile for Web Services (DPWS) standard, and exposes a set of services.

Lastly, the fourth element of the I2MS2C concept works with solutions to integrate the results of the previously described elements and furthermore provided a simulation environment for the evaluation of the overall I2MS2C concept. Here, the challenge of integrating IMS with SPSC are analyzed using simulation-based computational experiments and is intended to be evaluated in real-world case studies. Also, in order to achieve a proof-of-concept and an evaluation of the proposed concept, regarding to necessity to align the extended/developed intra-organizational planning methods as well as the coordination process, this element deals with the integration by aligning and fixing the interfaces between the developed concepts of the other thematic areas. Finally, the last part of this area relies on the validate of I2MS2C concept applying the methods proposed in cases studies, especially from the domain of ship building and the oil industry which both show the characteristics of slow moving and expensive components.

The main contribution of the I2MS2C concept is the integration of three different sub-systems: a distributed and networked embedded diagnostic system able to assess the error degradation of machinery/equipment and forecast the need for spare parts. A distributed decision-making sub-system for spare parts supply chain planning and coordination, responsible for tactical spare parts inventory and distribution planning as well as maintenance service planning concepts. An operational planning and scheduling system that is based on the information provided by the other sub-systems optimizes the operational production, transportation and inventory processes. Therefore, two decision-support models are need for the optimization of the systems. In the present paper, a supply chain with the I2MS2C concept fully implemented will be considered as the test case, which implies great data exchange among supply chain participants and deterministic demand of spare parts for maintenance in industries as the final clients.

\section{Communication Procedure Proposal}

The study developed in this paper is based on the study of a real case of a reference company in the production and distribution of spare parts for electric actuators in Brazil, which will be described hereafter in this work.

The supply chain in which the communication procedure will be based was first presented in [8], and consists of a simplified spare parts supply chain having a production facility that produces three types of products and has to attend, as final destination, the five biggest markets. The final clients of this supply chain are industries that buy these products as spare parts for maintenance on their production machines. In this supply chain, intelligent maintenance systems are used, that makes the demand visible for each one of the fifteen following days. The supply chain scheme is represented in Figure 1. 


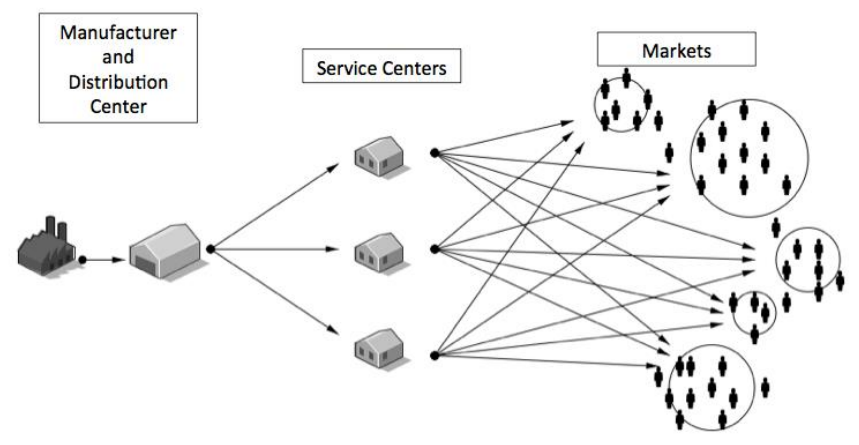

Fig. 1. Supply Chain Structure from a Spare Parts Supply Chain (Source: [8]) .

The communication procedure is shown on Figure 2 and it was modeled base on the model proposed in [10]. In the first step, the tactical optimization model is solved, using as input the predefined service level (defined in a previous strategic plan), minimum and maximum capacities per transportation mode and the demand per region (deterministic in this case). As outcome, the support-decision model will provide the inventory level desired per item per facility location, the service level in each region, the transport capacities required per transport mode and region, the emergency shipments capacities per region, the service personnel capacities required per service center and the production capacities required per item. Based on this outputs, tactical strategies will be studied and implemented in order to attend the settled goals. An analysis of the result of the plan shall be done to verify its feasibility and applicability. Otherwise, a feedback shall be given to the model to implement an internal adaptation and the model solved again. Then, the results of the tactical model will be used as boundaries and limitations for the operational planning. The operational plan will consider the allocated capacities and demands and will optimize the scheduling of the production and distribution throughout the supply chain on a daily basis. The results must be analyzed, and in case of unfeasibility or improvement opportunity, the feedback must be given to the model for an internal adaptation and the planning process re-executed. Otherwise, the result can be used to feedback the tactical plan, to verify its feasibility. If the operational plan is unfeasible, the desired standards are too high, and the boundaries given by the plan are too demanding to be achieved, and the tactical plan must be reviewed. Otherwise, the plan must be executed, and the supply chain monitored in other to verify if the results of the plans are being achieved. Otherwise, a feedback must be given to the decision-support models, to implement an external adaptation. 


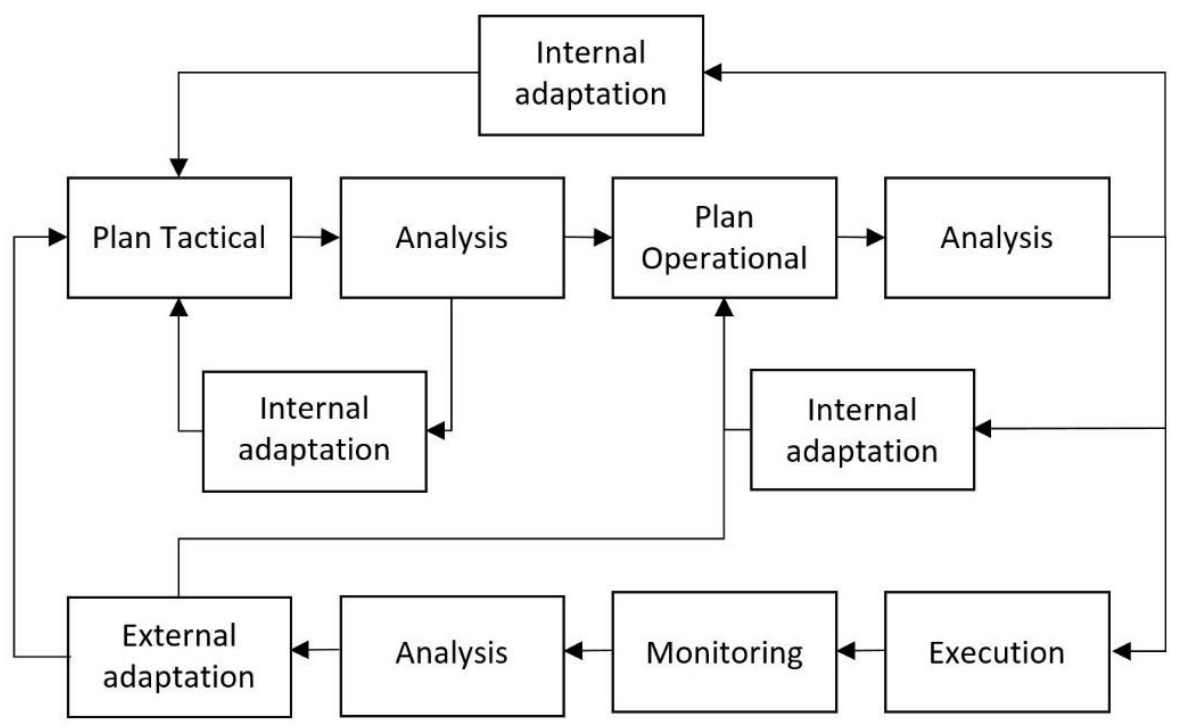

Fig. 2. Proposed communication procedure between tactical and operational decision-support models. (Source: author)

The communication procedure is guided to synchronize the execution of two mixed-integer linear problem (MILP) models developed in order to manage the already introduced spare parts supply chain. Summarizing, the tactical decision-support model will provided the objectives to be reach by the operational level, which will be executed and analyzed its feasibility by simulation in order to forecast the behavior of the results implemented with stochastic characteristics. The last result will feedback the tactical planning. When both plans converge, the output can be implemented on the real case, which will be also analyzed in order to feedback both support-decision models.

\section{Conclusion}

In the present work it was elucidated the importance and necessity of decision-support models in decision taking in supply chains. These models are designed in three different levels of wideness. These models generally do not consider the other levels decision, concluding that there is a lack in today's approaches concerning in communication between planning levels.

The work also introduces the concept about integrating intelligent maintenance systems and spare parts supply chain. A concept that can be shortly summarized being the use of electronic sensors in order to predict spare parts demands in industries combined with mathematical optimization models, both for tactical and operational levels, in order to provide lower costs on the supply chain while delivering higher service level. 
It was, as main objective of the paper, proposed a communication procedure between tactical and operational support-decision models in order to align different levels of planning. The procedure is recommended because no alignment between planning levels can reduce the efficiency and feasibility of the outcome plan, as well as a unique plan for more than one level could result in high computational cost. Using this procedure, it is possible to use more detailed optimization models in each planning level.

As future work directions it is recommended to develop support-decision models for each level in order to run a test application of the communication procedure. As well as an in-depth study about the possibility of including the strategic level in the procedure.

Acknowledgements This research was supported by the German Research Foundation (DFG) and the Brazilian Federal Agency for the Support and Evaluation of Graduate Education (CAPES) as part of the BRAGECRIM project "Integrating Intelligent Maintenance Systems and Spare Parts Supply Chains (I2MS2C)" (BRAGECRIM 022/2012).

\section{References}

1. Ivanov, D.: An Adaptive Framework for Aligning (re) Planning Ddecisions on Supply Chain Strategy, Design, Tactics, and Operations. International journal of production research, 48(13), 3999-4017 (2010)

2. Ivanov, D., Sokolov, B., Kaeschel, J.: A Multi-structural Framework for Adaptive Supply Chain Planning and Operations Control with Structure Dynamics Considerations. European Journal of Operational Research, 200(2), 409-420 (2010)

3. Christopher, M.: Logistics and Supply Chain Management: Creating Value-added Networks. Pearson Education (2005)

4. Narasimhan, R., Mahapatra, S.: Decision Models in Global Supply Chain Management. Industrial Marketing Management, 33(1), 21-27 (2004)

5. Espíndola, D., Frazzon, E.M., Hellingrath, B., and Pereira, C.E.: Integrating Intelligent Maintenance Systems and Spare Parts Supply Chain. Information Control Problems in Manufacturing, 14(1), 1017-1022 (2012)

6. Boylan J.E., Syntetos, A.A.: Spare Parts Management: A Review of Forecasting Research and Extensions. IMA Journal of Management Mathematics, 21(3), 227-237 (2010)

7. Huiskonen, J.: Maintenance Spare Parts Logistics: Special Characteristics and Strategic Choices. Int. J. Production Economics, 71(1-3), 125-133 (2001)

8. Israel, E.F.: Planejamento Operacional de Cadeias de Suprimentos de Peças de Reposição Integrado com Sistemas Inteligentes de Manutenção. Federal University of Santa Catarina, Florianópolis, Brazil (2014)

9. Djurdjanovic, D., Lee, J., Ni, J.: Watchdog Agent-an Infotronics-based Prognostics Approach for Production Performance Degradation Assessment and Prediction. Advanced Engineering Informatics, 17(3-4), 109-125 (2003).

10. Ivanov, D., Dolgui, A., Sokolov, B.: Applicability of Optimal Control Theory to Adaptive Supply Chain Planning and Scheduling. Annual Reviews in Control, 36(1), 73-84 (2012) 